\title{
Critical and creative research methods in social work
}

\author{
Lia Bryant (Ed), 2015 \\ Ashgate Publishing, Surrey, United Kingdom; Burlington, VT, USA. \\ ISBN 978-1-472-45829, pp. 235, hardback, NZD118.00
}

$\mathrm{I}$ was pleased to be able to review this particular book for this special issue of Aotearoa New Zealand Social Work with its theme of innovation and creativity. The brief for authors contributing to the special issue included creative methods in social work research and this book will resource those readers wanting to pursue creative and critical research approaches. There is an argument to be made that much social work research treads the fairly well worn paths of surveys, interviews and focus groups. So, a book promising to inspire new ideas is welcome.

Lia Bryant, as the editor of Critical and creative research methods in social work has assembled an excellent group of contributions in this edited collection. This is not a typical research methods book, although it absolutely deserves a place on the shelf of research methods teachers and supervisors of postgraduate research.

Bryant sets out to shift our research imagination as we attempt to answer complex questions via social work research. In the introduction, Bryant writes of the need for a "layering of approaches" using verbal accounts, texts and images as researchers have become "increasingly ill at ease with using interviews and focus groups as linear singular methods to analyse the complexity of people's lives" (p. 1). In this collection, Bryant curates some refreshing and exciting alternatives to traditional qualitative methods.

In the introductory chapter, Bryant challenges us as researchers to think hard about who we are in our research activities, exploring concepts of voice, positioning and reflexivity. I would recommend this chapter as a good starting point for critical social work researchers thinking about their design and how to ensure their research is anti-oppressive. Ensuring participant voice is central to qualitative work but the writing is inevitably in our author's voice as in the act of writing our perspectives and biases filter what we choose to include. Bryant notes the way "an academic argument is constructed and the selection of quotations .....are a representation of the vision and voice of the author" (p. 9).

Space does not allow an examination of all the chapters in this collection. All are worthwhile and I have chosen to focus on just three chapters to assist readers to gain a sense of what Bryant's collection offers.

Fatin Shabbar's fascinating discussion of her use of storytelling as a research method starts with an exploration of her postcolonial feminist standpoint. Storytelling does not impose the structure of traditional interviews which tend to pursue pre-determined topics and those contributing have greater control. Participants "set their boundaries, they select what to talk about and what to leave out, what is important and what is not" (p. 31). Shabbar describes a fascinating study exploring Iraqi women's experiences of war and militarisation. The stories told were very powerful and in the telling the women relocated themselves "within their stories, creating a new space and 
language" (p. 34). Reading this chapter, I was reminded of how powerful qualitative research can be to inform practice and to enrich our understanding of the experiences of those whose lives may have been so different to our own.

Mona Livholts' chapter presents a critical research approach of importance to social work via developing a deep understanding of how news media shape explanations of social problems. Livholts studied the media discourse concerning a serial sexual predator in Sweden. Her detailed and painful exploration of the way the story of rape was told in mass media led to an understanding that there were distinct discourses. Rapes perpetrated by men of non-Swedish ethnicity were explained primarily by culture. The crimes of Swedish men, in contrast, were attributed to alcohol and/or mental illness. Such observations have also been made about other incidences of violence, where quasireligious/political motives are ascribed to mass killings by men of colour while in the case of white perpetrators significant effort is made to find psychosocial explanations for acts we struggle to comprehend.

Livholts' work is summarised in this excellent chapter which contains illuminating examples of media analysis in which accompanying photos are seen as integral to the way news stories are framed. The chapter finishes with some collages of picture and text, curated by Livholts to demonstrate this framing. This is an important chapter for anyone exploring media representation of social problems which could be usefully applied to child welfare in Aotearoa New Zealand.

Fiona Buchanan's work draws on feminist use of creative arts-based research methods to explore sensitive phenomena. Having used clay work in therapy with survivors of trauma, Buchanan notes that in expression through the medium of clay, clients have been able to make meaning of experiences and understand the strengths with which they face adversity. "Clay effectively embodies and makes solid an interpretation of memories held in emotions.... The process is empowering as nothing is predetermined, both form and texture are in control of the maker" (pp. 192-193). Buchanan's chapter describes the employment of clay work as an expressive arts-based research method, exploring the experiences of women making a relationship with their babies while living in domestic violence. This is a rich account of a research process that is creative, respectful and empowering.

I would like to recommend this excellent edited collection to those who teach research methods and supervise student research. It is an inspiring collection and will be of interest to social workers who seek to use arts-based methods in practice, education and research. The promise of the book to inspire creative and critical research strategies is fulfilled. It does indeed open the research mind to new possibilities for an enriched understanding the social worlds we and our communities inhabit. 